\title{
Innovations in Polymer Applications - Plastic Packaging
}

\author{
Diogo Cardoso Rego ${ }^{1}$, Cíntia Sartor ${ }^{1}$, Nicolas Augusto Klayn ${ }^{2}$ and \\ Harrison Lourenço Corrêa ${ }^{1,3,{ }^{*}}$
}

\author{
${ }^{1}$ Postgraduate Program in Manufacturing Engineering, Laboratory of Polymer Materials, Technology Sector, \\ Department of Mechanical Engineering, Federal University of Paraná, 81530-000 Curitiba, PR, Brazil \\ ${ }^{2}$ Sector of Professional and Technological Education - SEPT, Curitiba, PR, Brazil \\ ${ }^{3}$ Federal Rural University of Rio de Janeiro, Institute of Technology, Department of Materials Engineering, \\ Seropédica, RJ, Brazil
}

\begin{abstract}
Polymer materials are used in several industrial sectors such as, paints and varnishes, packaging, and the automotive sector. The countless applications of this type of material stem from several factors such as lightness and ease of processing when compared to metals and ceramics. The possibility of chemical modification of polymers is worth mentioning, which can result in a new material with mechanical properties superior to those of the original ones. Another unique characteristic of polymer material is related to the ease with which they can be mixed with other elements (vegetable and synthetic fibers, metals, ceramics) to obtain a composite or hybrid material, thus expanding the spectrum of polymer applications. In this sense, the present work aims to show the uses of polymers in the packaging segment, addressing the main physicochemical and mechanical characteristics that are necessary for manufacturing packaging items as well as innovative technologies to obtain those materials.
\end{abstract}

Keywords: Polymer, film, packing, product, researches.

\section{INTRODUCTION}

Polymer materials have been part of modern society for decades now, allowing new areas of activity to be developed, and work fronts to be implemented. There are numerous examples in which the emergence of a new polymer has impacted the industry, the productive sector, and the consumption pattern. The large-scale production of natural rubber that, together with the development of the sulfur vulcanization process, allowed for new applications in damping systems, seals, etc.; the synthesis of cellulose nitrate, considered to be the first synthetic polymer produced by men - in 1846 -, first employed as a propellant and later in photographic films; the use of styrene mixed in synthetic rubbers, in 1930; the synthesis of nylon, in the 1930s; and the emergence of Teflon, in 1941 [1]. Polymer composites and hybrid materials also allow advances in certain sectors. The naval and aeronautical industry uses these materials as a way of reconciling good mechanical properties with lightness, combined with resistance to corrosion [2]. Despite the controversy surrounding these materials - since most of them are obtained through processes that use oil and gas-based inputs and, therefore, from non-renewable sources -, many efforts are being made to obtain sustainable polymers. In line with the circular

*Address correspondence to this author at the Postgraduate Program in Manufacturing Engineering, Laboratory of Polymer Materials, Technology Sector, Department of Mechanical Engineering, Federal University of Paraná, 81530-000 Curitiba, PR, Brazil; Tel: +55 $413361-3123$;

E-mail: harry.lou.correa@gmail.com production process, many researchers have already developed production techniques with which it is possible to obtain polymers from renewable sources, the so-called 'sustainable polymers' [3]. Polyhydroxyalkanoates (PHAs) and poly(lactic acid) (PLA) are some examples of biopolymers, the latter having good mechanical properties and low cost [4] besides having several biomedical applications [5]. Even so, polymers and their composite and hybrid derivatives have much to contribute to maintaining the quality of human life. The present work aims to address some industrial applica-tions in which the use of polymers is fundamental to guarantee the quality of the product and/or process, showing some innovations in the area of polymer materials geared towards the packaging sector.

\section{METHODOLOGY}

Data collection was based on consultations with sciencedirect.com, to which keywords related to the packaging area were submitted. The choice of this segment was based on the following criteria: importance of productive sector, environmental impact, and food safety. Regarding the collection of scientific articles related to innovation, the search period was limited to the period from 2000 to 2020 . The keywords used were: packaging food, migration, safety food, polymers for food, food packaging materials.

\section{POLYMERS IN THE PACKAGING INDUSTRY}

In general, the materials used in packaging are paper, corrugated cardboard, carton, wood, plastic, 
metal (aluminum and steel), and glass. These materials can be combined in several ways and shapes to obtain good quality packaging at competitive costs. Different types of plastic packaging are applied during the production process of many consumer products. They can be classified as primary, secondary and tertiary, depending on what they involve and at what stage of production they are applied [6]. In this article, the focus is on the primary packaging, which are in direct contact with the final consumer and whose application concentrates on ensure protection to the product and hygiene.

On average, polymeric films for packaging have a thickness between $10 \mu \mathrm{m}$ and $250 \mu \mathrm{m}$, depending on factors such as durability, chemical barrier and resistance [6]. Cellulosic materials have mainly the function of structuring the packaging, giving it various shapes, which facilitate handling, stacking, and transport, while giving low weight to packaging. They have an adequate surface for most different types and quality of printing [7]. The combination of cellulosic materials with conventional polymer films from petroleum or renewable sources - biopolymers results in improved surface finishes and functional properties. This contributes to the provision of permeability features to water vapor, oil, and gases, in addition to enabling packaging sealing when tightness is required [8].

\subsection{Paper Packaging Technology}

Regardless of the type of packaging, technologies and researches explore materials that are less aggressive to the environment with reduced grammage, renewable raw materials, improvement in the substrate properties with the development of materials that support the load and preserve the quality of the content. Buchner [9] reports that $33 \%$ of all food available for human consumption ends up not being used at all. Among many factors that impact this number between the harvest and the final consumer, packaging plays an important role in this chain - mainly by maintaining the characteristics of the products - and may contribute to the reduction of those negative numbers. Therefore, lower consumption of raw material in the development of packaging cannot be neglected to the detriment of the integrity of the content. Currently, the demand for sustainable packaging has required the development of technologies where the polymeric film is biodegradable. Materials based on corn starch, cellulose, chitosan and proteins of animal and vegetable origin are interesting options, as they are low-cost, from renewable and biocompatible sources $[10,11]$.

\subsection{Polymers Used in Cellulosic Material Coatings}

According to Kuan and Benazzi [9], coatings applied to paper surfaces may be produced for printing, when one wants to improve printing quality; for decorative purposes, when the aim is to improve the appearance of paper; and for functional purposes, when one wants to promote some specific property, such as resistance to moisture, gas, oil, and fat, which are the most sought after by the packaging sector [7]. Among the polymer coatings available, the most common for packaging are polyethylene (PE), polypropylene (PP), polystyrene (PS), polyvinyl chloride (PVC), polyethylene terephthalate (PET), and the ethylene/vinyl alcohol copolymer $(\mathrm{EVOH})$ that, combined with paper from multilayer lamination or extrusion processes, can promote high permeability characteristics $[12,6]$.

\subsection{Factors that Influence Polymer-Paper Adhesion}

Lamination is not a simple process and, in general, requires many steps during the passage of the product through specific equipment. On the other hand, paper can be printed and coated for fusion sealing in a single operation. This combination reduces steps in the transformation process and, consequently, lowers production costs.

There are four basic methods of lamination: by water-based adhesives or another solvent, which requires evaporation of the laminated vehicle to combine the substrates; by thermoplastic coating, which requires heat and pressure to laminate; by extrusion, in which a layer of molten plastic is applied onto a moving sheet of paper or film; and by hot melt coating, which differs from extrusion coating in that it is made at a lower temperature with a mixture of wax and other materials at a low melting point [13].

According to Ghanem and co-authors [14], due to its complexity, the adhesion mechanism cannot be explained just by one factor. So far, the following theories address this issue: mechanical interactions, electrostatics, diffusion, wetting, chemical adhesion, a weak adhesion layer, and the acid-base theories - the last four are based on the adsorption reaction by the surface.

For Zhao and co-authors [13], the quality of polymer adhesion to paper is determined by adhesion resistance to mechanical stresses in terms of rupture 
stress, referred to as 'practical adhesion'. At this point, it is necessary to do distinguish 'adhesion' from 'adhesion force'. Once an adhesion bond has been formed, forces in the interface - such as the van der Walls forces and the acid-base interactions involved in the adhesion bond - are no longer a concern, since substrate separation is no longer susceptible to failure. This distinction is useful to understand the behavior of polymer/paper laminates. The formation of adhesion bonds with paper is an easy process due to its high superficial energy and porous structure. However, when compared to glass and plastic, the paper is a weak substrate and may suffer tearing or delamination when shear forces are applied between paper and the laminated polymer.

When the lamination method includes the application of adhesives, a sufficient amount of them must be used in the interface between the materials. These must have an affinity with the adhesive used. Such interaction is especially important for polymers that have low surface tension and end up repelling the adhesive. In order to avoid this problem, a superficial treatment must be carried out aiming to increase surface tension. One of the treatments used to produce surface tensions on an industrial scale is Corona treatment. It consists of the application of electrical discharges capable of uniformly modifying the polymer surface. This discharge leads to the generation of reactive oxidants - such as ozone, oxygen freeradicals, or oxygen atoms - responsible for moistening the surface, thus facilitating adhesion [15].

For the method with a coating applied by extrusion, the polymers used are preheated so that they can spread out and, when they come into contact with the paper, they establish molecular adhesion forces. Thermodynamically, the polymer adhesion propensity is described by the concepts of 'surface energy' or 'interface energy' and by the work of adhesion and cohesion. In the contact region, the heated polymer is solubilized on paper forming the third phase with both substrates diffuse between themselves [16]. In order to fully use the polymer potential as coating, it must remain on the surface and not penetrate the base paper [17].

\subsection{Permeability}

Permeability is a very important property for the packaging industry. Many packaged products are sensitive to water vapour or gases present in the environment where the packages are stored. Controlling the acceptable quantity that these components can permeate into the package is crucial for maintaining the quality of the product until it is opened by the consumer. This way, water vapour or gas permeability values of polymer films can be used to predict the shelf-life of packaged products and indicate specific applications for them [18]. Permeability to water vapour depends on the relative humidity of the air and the hygroscopic properties of the material used, in addition to the pressure differential that determines the driving force, since the diffusion direction can occur from a higher to a lower pressure [19]. The permeation process through the materials occurs in four stages: first, there is the absorption of water vapour or gas on the surface; second, there is the solubilization in the matrix; third, there is diffusion through the material wall; and finally, there is desorption on the other surface, that in contact with the packaged product [20].

\subsubsection{Water Vapour Permeability (WVP) and to Oxygen (PO)}

Many undesirable reactions - such as oxidation, vitamin degradation, enzymatic reactions, and microbial reactions that reduce the shelf-life of food are controlled by the water activity [21]. Mourad [7] reports that resistance to moisture absorption means that moisture penetrates at a low speed. The property that determines the resistance of paper to humidity is the water vapour permeability rate (WVPR), determined according to the ASTM E96 2016 standard. According to this standard, permeability is the rate of water vapour propagation per unit of area of flat material of unitary thickness induced by a difference in vapour pressure between two specific surfaces under fixed conditions of temperature and moisture.

In order to obtain a good barrier material - that is, a barrier to gas and a barrier to water vapour -, a polymer must have some properties such as a high glass transition temperature $(\mathrm{Tg})$, high chain rigidity and macromolecule packaging capacity, interaction between polymer chains [21]. The Crystallinity of the barrier material is important because a crystalline network is usually impermeable and increases tortuosity [22]. In addition to crystallinity, the polarity of the barrier material is also important for the oxygen barrier. An increase in material polarity leads to less permeability to oxygen [21].

\subsection{Innovation}

The current trend is that packaging fulfills more than its main function of protecting the filling and is also committed to producing lower $\mathrm{CO}_{2}$ throughout the 
packaging life cycle. Renewable materials and nanomaterials, acting as smart reinforcements in the polymer matrices, have been developed to increase the packaging properties in the face of these contemporary requirements [23].

Biopolymers have gained attention in several applications following researches advances in disciplines related to packaging. The reduction of environmental impact, due to the renewable origin of the raw material still promotes unique properties when compared to conventional polymers from fossil sources. Another factor that makes biopolymers preferable is their affinity with fillings that, in some situations, function as active packaging providing improvement in the quality and safety of those foods [24]. An alternative to the thermoplastic resins traditionally used by the productive sector, the guar gum (taken from Cyamopsis tetragonolobus) can stand out in the market. The biopolymer film of guar gum can be formed using the polymer casting method. One of the additives incorporated into the polymer is polyvinylic alcohol, which can enhance mechanical properties and biocompatibility. The advantage of it is the fact it is not carcinogenic. It has good thermal and physical properties and a high expansion rate in aqueous solutions. The use of chitosan - a substance with bactericidal and fungicidal properties [25] in its formulation - allows obtaining a homogeneous, transparent and bubble-free film [26].

Polymers obtained from renewable sources are ecological alternatives to the synthetic ones. However, they are at a disadvantage regarding the desired barrier properties. As a complement to the properties of biopolymers regarding barrier, reinforcements on a nanometric scale appear as co-adjuvants for they provide considerable gains even when used in low concentrations. Nanoclays, nanocellulose, and plant nanofibers, for example, have been studied in order to improve mechanical properties, microbial activities, barrier increase, and thermal behavior [27-29].

Using $10 \%(\mathrm{w} / \mathrm{w})$ nanocrystals and $2.5 \%(\mathrm{w} / \mathrm{w})$ cellulose nanofibers as a coating on kraft paper and soy protein as the matrix, Tyagi [30] observed that, in the obtained film, there was a 260 -times reduction in the permeability to oxygen, $30 \%$ reduction in the permeability rate to water vapor and in the kit test to check the barrier to fat leaving kit 0 to kit 11 , when compared to uncoated paper.

Combining 1 to $3 \%(\mathrm{w} / \mathrm{w})$ nanoclay with the same quantity of cellulose nanofibers in a PLA matrix, Sillard and co-authors showed that the produced film reached a $90 \%$ reduction in the oxygen permeability rate and a $76 \%$ reduction in the water vapor permeability rate, when compared to pure PLA.

Studies on coatings with the application of silicon oxide $\left(\mathrm{SiO}_{\mathrm{x}}\right)$ by the plasma jet technique at atmospheric pressure have been conducted because they promote significant improvement in the barrier properties to oxygen and moisture. This technique is preferable for its lower complexity when compared to other techniques that have been developed: evaporation, spraying, chemical vapor deposition, and chemical deposition enhanced by plasma, in addition to being able to be applied to polymer films [31].

\section{POLYMERS FOR FROZEN PRODUCT PACKAGING}

The meat production chain is perhaps the one that most uses polymeric films for packaging. This is because the frozen product must have a long useful life in order not to perish during international and national distribution logistics [6]. This primary barrier, generally based on polymers, needs to inhibit the product's exposure to oxygen, heat and light [32].

Among the polymers used in refrigerated and/or frozen food packaging, polyethylene (PE) stands out, which, with its high oxygen permeability characteristics and excellent behavior at low temperatures. It is ideal for packaging fresh meat and frozen chicken. Another prominent polymer that can be used for packaging meat food is the polyvinyl chloride (PVC). Even with the need to use additives in its formulation, this one can be used to protect stored meat. The development of food packaging requires a preliminary understanding of the product's behavior under storage and stock conditions. Thus, it is not enough to design a film that is only flexible or biodegradable. Other factors must be taken into account, such as controlling the migration of chemical agents, including odors, oxygen, water and $\mathrm{CO}_{2}$. Cheese packaging, for example, requires an understanding of the dynamics of the packaged product. During the ripening process, Emmental cheese emits $\mathrm{CO}_{2}$, which needs to be purged, and propionic acid. In this process, the entry of oxygen must be prevented, while water vapor must be kept inside the package [33].

\subsection{Physicochemical Properties of Packaging for Refrigerators}

The growth of deteriorating microorganisms, the oxidation of pigments and the enzymatic activity are 
favored by the gaseous composition of the atmospheric air and other gases inside the packaging. One of the determinants of deterioration interference inside food packaging is the atmosphere around the product. This factor also determines the growth rate of microorganisms. One of the techniques used for reducing deterioration of meat products is to replace air inside the packaging with a mixture of active gas with antimicrobial action. This is possible through an injection of $\mathrm{CO}_{2}$ or by using vacuum packaging [34].

The technique of modifying the atmosphere inside, the packaging can be classified as active or passive. The passive one is used in cases in which the products need to breathe for their conservation, as in the case of fruit and vegetables. The modified-atmosphere technology for non-living products is active. Active packaging and the active oxidizing packaging are based on the inclusion of active agents in packaging that interacts with the meat - or another content -, containing natural or synthetic antioxidant agents inactive compounds that protect the product from lipid oxidation [35-37].

Technologies associated with oxygen absorbers use one or more of the following principles: Ironpowder-based compounds; low molecular weight reducing organic substances; enzymatic systems; ironreducing components; polymer resins; fatty acids; biological oxygen absorber; sulfite and its analogues [37].

There are two groups of films for oxidizing packaging. The classification depends on whether the antioxidant compound is on the surface or whether it is incorporated into the polymer [37]. When an antioxidant packaging with active compounds incorporated in the polymer matrix is produced, the antioxidant is mixed with the polymer by dissolving both in an appropriate solvent (molding procedure) or by melting the antioxidant with the polymer (extrusion procedure). The other technique consists of immobilizing the antioxidants on the polymer surface, which were previously treated through physical or chemical methods in order to favor adhesion to the active compound (coating procedure) [38].

The characteristics of the polymer matrix and food, and the type of antioxidant used are factors that influence the release of antioxidant compounds and the release rate can be increased with the addition of plasticizers to the polymer matrix.

\subsection{Innovations in the Area of Packaging for Refrigerators}

Packaging alternatives have been studied by the meat industry due to the deterioration of meat products and due to the growth of microorganisms during processing and storing of the product. Lipid oxidation is the main cause of deterioration in meat products due to their perishable characteristics, their high fatty acid content, and their amounts of fat. For these characteristics, together with the scientific community, the meat industry has been studying new packaging named 'active antioxidant packaging'. They have as a principle the addition of active compounds able to interact with the environment avoiding lipid oxidation. Butylated hydroxyanisole is an example of synthetic antioxidants used in the polymer matrix with a protective function against lipid oxidation. However, with the consumption trend directed to more natural products, the packaging market has been forced to develop packaging with natural antioxidants [38].

Research on the use of natural types of antioxidants is still under development. However, studies are showing the efficacy of some compounds that present significant results in their use and in replacing synthetic antioxidants. Active films incorporated by coating techniques with natural antioxidants - such as rosemary - have suppressed lipid oxidation and prevented the formation of secondary lipid oxidation products. Another example of using a film with a natural oxidant is the result of the compound obtained by the casting method of a biopolymer matrix - potato starch, for example - with $5 \%$ green tea as a natural antioxidant. In these studies, the samples presented lower ratios of lipid oxidation and an enhancement in stability of the reddish color of meat [38].

Other natural antioxidants studied as packaging additives are cocoa and coffee. This is so because they are sources of polyphenols and flavonoids with antioxidant capacity. They are safe when in contact with food, in addition to having great availability. The simultaneous use of cocoa and coffee can result in an enhanced synergistic antioxidant effect, as they result in linked antioxidants instead of free antioxidants. The use of cocoa and coffee as additives to the polymer, in addition to pigmenting the packaging, gives the film water vapor permeability. Thus, packaging resistance to catalytic oxidation of food is increased by the action of water or light [39].

Recent studies show the development of smart packaging - which, in many cases, are just modified 
nanomaterials that can indicate a certain quantifiable chance - and composites in nanoscales. One of the aspects of smart packaging is the material itself. Nanocomposites are impermeable to some components, such as oxygen, light, moisture, and some gases, which increase product deterioration and microbial activity. Thus, smart packaging interacts with food and gradually releases its active nanomaterials, preventing deterioration and an increase in microbial activity. Silver nanoparticles are usually used for this purpose [40], aiming to reduce one of the major problems of the food sector: the deterioration of products and its consequences for public health. The first chemical agents used in active packaging were organic acids, enzymes and polymers. In recent years, however, metal nanoparticles or metal oxides have been used due to their stability in the face of processing conditions [41]. Nanoparticles based on magnesium oxide, copper oxide, zinc oxide, titanium and silver have been investigated as fillers for polymer films, due to the antibacterial activity of these metals [42-44]. Thanks to chemical stability, ease of chemical modification and non-flammable characteristics, PVC is widely used by the packaging industry, including as a matrix for nanocomposites. Shimoga and co-authors [45] evaluated composites of PVC-silver nanoparticles (silver nanoparticles-polyvinylchloride composites) for film composition. In their studies based on the doping of silver nanoparticles, the authors verified a homogeneous distribution of the particles in the polymeric matrix, for stoichiometric concentrations between 2.5 and 10\%, as well as an increase in thermal stability. Silver nanoparticles, AgNPs, have a broad spectrum of antibacterial activity, including Gram-positive and negative bacteria, fungi and viruses [46]. And for that reason, they attract interest from the packaging industry.

Because nanoparticles have more reactive characteristics than other particles, nanotechnology has raised concerns in countries like the USA, which has led to the publication of regulatory standards for different classes of nanomaterials. Currently, these standards present divergences regarding the use of packaging. It is, therefore, crucial to check the toxicity of nanoparticles in the industrial production of food packaging [40]. Li and co-authors [47], for example, found that the migration of silver ions present in a film based on lactic polyacid (PLA) increased with the storage time of the packaged product (cottage cheese). In his studies under simulated conditions, Echegoyen [44] verified the migration of silver particles from the polymeric packaging to the content. However, with values below the limit established by European regulations.

\section{CONCLUSIONS}

The review of the literature shows that important research has been carried out in the last 3 years regarding the application of polymers in packaging. Film production based on biopolymers and modifications in formulations - such as the inclusion of natural antioxidants - are some alternatives adopted and stimulated by the productive sector. Despite global efforts to reduce the use of plastic packaging, the need to store food products demands an intense Research and Development (R\&D) work on new materials that reconcile market and sustainability. In this sense, polymers will still be highlighted in the coming years, bringing challenges both for researchers and manufacturers.

\section{REFERENCES}

[1] Biermann C. Handbook of pulping and papermaking. Academic Press 1996. https://doi.org/10.1016/B978-012097362-0/50026-1

[2] Neser G. Polymer based composites in marine use: History and future trends. Procedia Engineering 2017; 194: 19-24. https://doi.org/10.1016/j.proeng.2017.08.111

[3] Hong M, Chen E. Future directions for sustainable polymers. Trends in Chemistry 2019; 1(2): 148-151. https://doi.org/10.1016/j.trechm.2019.03.004

[4] Raquez J, Habibi Y, Murariu M, Dubois P. Polylactide (PLA)based nanocomposites. Progress in Polymer Science 2013; 38(10-11): 1504-1542. https://doi.org/10.1016/j.progpolymsci.2013.05.014

[5] Farah S, Anderson D, Langer R. Physical and mechanical properties of PLA and their functions in widespread applications - a comprehensive review. Advance Drug Delivery Reviews 2016; 107(15): 367-392. https://doi.org/10.1016/j.addr.2016.06.012

[6] Barlow C, Morgan D. Polymer film packaging for food: An environmental assessment. Resources, Conservation and Recycling 2013; 78: 74-80. https://doi.org/10.1016/j.resconrec.2013.07.003

[7] Mourad A. Boletim Técnico do Centro de Tecnologia de Embalagem do Instituto de Tecnologia de Alimentos, Campinas 1996; 8(1).

[8] Alcan alumínio do Brasil S.A. Divisão de embalagens flexíveis. Portfólio. Mauá: Alcan 1997.

[9] Buchner B, Fischler C, Gustafson E, Reilly J, Riccardi G, Ricordi C, Veronesi U. Food waste: causes, impacts and proposals. Barilla Center for Food \& Nutrition 2012: Available from: https: //www.barillacfn.com/m/publications/food-wastecauses-impact-proposals.pdf

[10] Kuan G, Benazzi R. Colagem superficial e revestimento. In: D'Almeida MLO. (Coord.) Celulose e Papel: tecnologia de fabricação do papel. São Paulo: IPT/SENAI 1998; pp. 761762.

[11] Herniou-Julien C, Mendieta J, Gutiérrez T. Characterization of biodegradable/non-compostable films made from cellulose acetate/corn starch blends processed under reactive extrusion conditions. Food Hydrocolloids 2019; 89: 67-79. https://doi.org/10.1016/j.foodhyd.2018.10.024 
[12] Zhong $Y$, Godwin P, Jin Y, Xiao H. Biodegradable polymers and green-based antomicrobial packaging materials: A minireview. Advanced Industrial and Engineering Polymer Research 2020; 3: 27-35

https://doi.org/10.1016/j.aiepr.2019.11.002

[13] Barão M. Embalagens para produtos alimentícios. Dossiê Técnico 2011; p. 31

[14] Hanlon J. Handbook of package engineering, New York: McGraw-Hill 1971.

[15] Ghanem A, Lang Y. Introduction to polymer adhesion. Department of process engineering and applied science, Dalhousie University, Halifax, Nova Scotia, Canada 2017.

[16] Desai SM, Singh RP. Surface modification of polyethylene; Adv Polym Sci 2004; 169: 231-293. https://doi.org/10.1007/b13524

[17] Zhao B, Kwon $\mathrm{H}$. Adhesion of polymers in paper products from the macroscopic to molecular level - An overview. Journal of Adhesion Science and Technology 2010; 25: 6-7. https://doi.org/10.1163/016942410X525821

[18] Kjellgren H. Barrier properties of greaseproof paper, Karlstad University Studies, Karlstad, Sweden 2005

[19] Mchugh T, Krotcha J. Sorbitol vs. glycerol - plasticized whey protein edible films: integrated oxygen permeability and tensile property evaluation. Journal for Agricultural and Food Chemistry $1994 ; 42(4)$ https://doi.org/10.1021/jf00040a001

[20] Larotonda F, Matsui K, Sobral P, Laurindo J. Hygroscopicity and water vapor permeability of Kraft paper impregnated with starch acetate. Journal of Food Engineering 2005; 71(4): 394-402.

https://doi.org/10.1016/j.jfoodeng.2004.11.002

[21] Roy S, Gennadios A, Weller C, Testin R. Water vapor transport parameters of a cast wheat gluten film. Industrial Crops and Products 2000; 11(1): 43-50. https://doi.org/10.1016/S0926-6690(99)00032-1

[22] Robertson G. Food Packaging Principles and Practice. Marcel Dekker Inc, New York, USA 1993.

[23] Hedenqvist $M$, Gedde U. Diffusion of Small-Molecule Penetrants in Semicrystalline Polymers. Progress in Polymer Science 1996; 21(2): 299-333. https://doi.org/10.1016/0079-6700(95)00022-4

[24] Moustafa H, Youssef A, Darwish N, Abou-Kandill A. Ecofriendly polymer composites for green packaging: Future vision and challenges. Composites Part B: Engineering 2019; 172: $16-25$

https://doi.org/10.1016/j.compositesb.2019.05.048

[25] Youssef A, El-Sayed S, Salama H, Assem F, Abd M. Novel bionanocomposite materials used for packaging skimmed milk acid coagulated cheese (Karish). International Journal of Biological Macromolecules 2018; 115: 1002-1011.

https://doi.org/10.1016/j.ijbiomac.2018.04.165

[26] Dehghani S, Hosseini S, Regenstein J. Edible films and coatings in seafood preservation: A review, Food Chemistry 2018; 240: 505-513.

https://doi.org/10.1016/j.foodchem.2017.07.034

[27] Bashir A, Jabeen S, Gull N, Islam A, Sultan M, Ghaffar A, Khan S, Iqbal S, Jamil T. Co-concentration effect of silane with natural extract on biodegradable polymer films for food packaging, International Journal of Biological Macromolecules 2018; 106: 351-359. https://doi.org/10.1016/j.ijbiomac.2017.08.025

[28] Li H, He Y, Yang J, Wang X, Lan T, Peng L. Fabrication of food-safe superhydrophobic cellulose paper with improved moisture and air barrier properties. Carbohydrate Polymers 2019; 211: 22-30.

https://doi.org/10.1016/i.carbpol.2019.01.107
[29] Ferrer A, Pal L. Hubbe M. Nanocellulose in packaging: Advances in barrier layer technologies. Industrial Crops and Products 2017; 95: 574-582. https://doi.org/10.1016/j.indcrop.2016.11.012

[30] Sillard C, Trifol J, Plackett D, Szabo P, Bras J, Daugaard A Hybrid poly(lactic acid)/nanocellulose/nanoclay composites with synergistically enhanced barrier properties and improved thermomechanical resistance. Polymer International 2016; 65: 988-995. https://doi.org/10.1002/pi.5154

[31] Tyagi P, Lucia L, Hubbe M, Pal L. Nanocellulose-based multilayer barrier coatings for gas, oil, and grease resistance. Carbohydrate Polymers 2019; 206. https://doi.org/10.1016/j.carbpol.2018.10.114

[32] Zhang H, Guo Z, Chen Q, Wang X, Wang Z, Liu Z. Deposition of silicon oxide coatings by atmospheric pressure plasma jet for oxygen diffusion barrier applications. Thin Solid Films 2016; 615 https://doi.org/10.1016/j.tsf.2016.06.042

[33] Hu K, Huyan Z, Ding S, Dong Y, Yu X. Investigtion on food packaging polymers: Effects on vegetable oil oxidation. Food Chemistry 2020; 315. https://doi.org/10.1016/.j.foodchem.2020.126299

[34] Mortensen G. Putting packaging first. In $5^{\text {th }}$ IDF Symposium on Cheese Ripening 2008.

[35] Guerreiro T, Oliveira D, Melo C, Lima E, Catharino R. Migration from plastic packaging into meat 2018. https://doi.org/10.1016/i.foodres.2018.04.026

[36] Adilah Z, Hanani Z. Active packaging of fish gelatin films with Moranda citrifolia oil. Food Bioscience 2016; 16. https://doi.org/10.1016/j.fbio.2016.10.002

[37] Martucci J, Gende L, Neira L, Ruseckaite R. Oregano and lavender essential oils as antioxidant and antimicrobial additives of biogenic gelatin films. Industrial Crops and Products 2015; 71: 205-213. https://doi.org/10.1016/j.indcrop.2015.03.079

[38] Sarantópoulos C, Cofcewicz L. Embalagens ativas para produtos perecíveis. Instituto de Tecnologia de Alimentos. Boletim de Tecnologia e Desenvolvimento de Embalagens 2016; 28: 1-12.

[39] Domínguez R, Barba F, Gómez B, Putnik P, Kovacevic D, Pateiro M, Santos E, Lorenzo J. Active packaging films with natural antioxidants to be used in meat industry: A review. Food Research International 2018; 113: 93-101. https://doi.org/10.1016/j.foodres.2018.06.073

[40] Santos P, Silva L, Souza C, Alburquerque E, Druzian J. Coffee-cocoa additives for bio-based antioxidant packaging. Food Packaging and Shelf Life 2018; 18: 37-41. https://doi.org/10.1016/j.fpsl.2018.08.005

[41] Madhusudana P, Chellukuria N, Shivakumar N. Smart packaging of food for the 21st century - A review with futuristic trends, their feasibility and economics. Materials Today: Proceedings 2018; 5(10): 21018-21022. https://doi.org/10.1016/j.matpr.2018.06.494

[42] Carbone M, Donia D, Sabbatella G, Antiochia R. Silver nanoparticles in polymeric matrices for fresh food packaging Journal of King Saud University - Science 2016; 28: 273-279. https://doi.org/10.1016/j.jksus.2016.05.004

[43] AbdelRahim K, Mahmoud S, Ali A, Almaary K, Mustafa A Husseiny $S$. Extracellular biosynthesis of silver nanoparticles using Rhizopus stolonifer. Saudi Journal of Biological Sciences 2017; 24(1): 208-216. https://doi.org/10.1016/j.sjbs.2016.02.025

[44] Almeida A, Franco A, Peixoto F, Pessanha K, Melo N. Application of nanotechnology in food packaging. Polímeros 2015; 25: 89-97. https://doi.org/10.1590/0104-1428.2069 
[45] Echegoyen Y, Nérin C. Nanoparticle release from nano-silver antimicrobial food containers. Food and Chemical Toxicology 2013; 62: 16-22.

https://doi.org/10.1016/j.fct.2013.08.014

[46] Shimoga G, Shin E, Kim S. Silver nanoparticles incorporated PVC films: Evaluation of structural, thermal, dielectric and catalytic properties. Polímeros 2019; 29: 1-9.

https://doi.org/10.1590/0104-1428.08218

[47] Kanmani P, Lim S. Synthesis and structural characterization of silver nanoparticles using bacterial exopolysaccharide and its antimicrobial activity against food and multidrug resistant pathogens. Process Biochemistry 2013; 48: 1099-1106. https://doi.org/10.1016/j.procbio.2013.05.011

[48] Li W, Li L, Zhang H, Yuan M, Qin Y. Evaluation of PLA nanocomposite films on physicochemical and microbiological properties of refrigerated cottage cheese. Journal of Food Processing and Preservation 2018; 42: 1-9. https://doi.org/10.1111/jfpp.13362

Received on 16-03-2020

Accepted on 13-04-2020

Published on 18-04-2020

DOI: https://doi.org/10.6000/1929-5995.2020.09.02

(c) 2020 Rego et al.; Licensee Lifescience Global.

This is an open access article licensed under the terms of the Creative Commons Attribution Non-Commercial License (http://creativecommons.org/licenses/by-nc/3.0/) which permits unrestricted, non-commercial use, distribution and reproduction in any medium, provided the work is properly cited. 